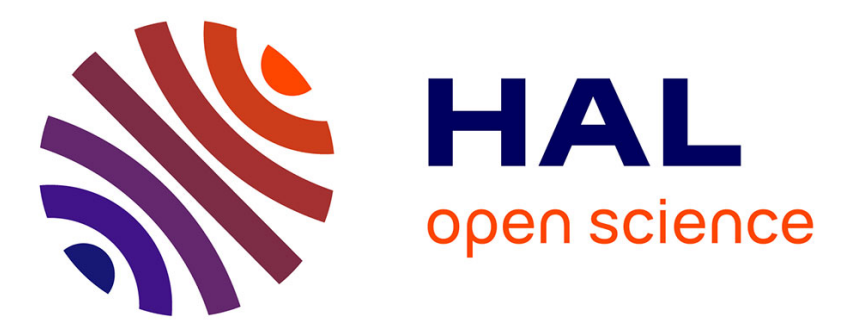

\title{
Seasonal variation of gravity wave activity at midlatitudes from 7 years of COSMIC GPS and Rayleigh lidar temperature observations
}

Sergey Khaykin, Alain Hauchecorne, Nahoudha Mzé, Philippe Keckhut

\section{- To cite this version:}

Sergey Khaykin, Alain Hauchecorne, Nahoudha Mzé, Philippe Keckhut. Seasonal variation of gravity wave activity at midlatitudes from 7 years of COSMIC GPS and Rayleigh lidar temperature observations. Geophysical Research Letters, 2015, 42 (4), pp.1251-1258. 10.1002/2014GL062891 . hal-01109116

\author{
HAL Id: hal-01109116 \\ https://hal.science/hal-01109116
}

Submitted on 19 Jul 2020

HAL is a multi-disciplinary open access archive for the deposit and dissemination of scientific research documents, whether they are published or not. The documents may come from teaching and research institutions in France or abroad, or from public or private research centers.
L'archive ouverte pluridisciplinaire HAL, est destinée au dépôt et à la diffusion de documents scientifiques de niveau recherche, publiés ou non, émanant des établissements d'enseignement et de recherche français ou étrangers, des laboratoires publics ou privés. 


\section{Geophysical Research Letters}

\section{RESEARCH LETTER \\ 10.1002/2014GL062891 \\ Key Points: \\ - Synergetic use of different observation techniques for studying gravity waves \\ - Gravity wave activity distribution is set by the wave-mean flow interactions \\ - Wind divergence can be used as a proxy for locating gravity wave hot spots}

Correspondence to:

S. M. Khaykin,

Sergey.Khaykin@latmos.ipsl.fr

\section{Citation:}

Khaykin, S. M., A. Hauchecorne, N. Mzé, and P. Keckhut (2015), Seasonal variation of gravity wave activity at midlatitudes from 7 years of COSMIC GPS and Rayleigh lidar temperature observations, Geophys. Res. Lett., 42, 1251-1258, doi:10.1002/ 2014 GL062891.

Received 16 DEC 2014 Accepted 16 JAN 2015 Accepted article online 23 JAN 2015 Published online 24 FEB 2015

\section{Seasonal variation of gravity wave activity at midlatitudes from 7 years of COSMIC GPS and Rayleigh lidar temperature observations}

\author{
S. M. Khaykin ${ }^{1}$, A. Hauchecorne ${ }^{1}$, N. Mzé ${ }^{1}$, and P. Keckhut ${ }^{1}$ \\ ${ }^{1}$ LATMOS/IPSL, UVSQ, CNRS-INSU, Guyancourt, France
}

\section{Introduction}

The importance of gravity waves (GW) for global atmospheric circulation, variability, and structure is now well recognized [e.g., Alexander et al., 2010]. The main sources of GW include flow over orography, convection, and imbalances in jet/fronts systems [Fritts and Alexander, 2003]. Existing at a wide range of horizontal scales and intrinsic frequencies [e.g., Holton, 1992], gravity waves and their effect on the mean flow pose a major difficulty for general circulation models. Due to insufficient spatial resolution, these models cannot describe the full spectrum of waves explicitly and, hence, need parameterization to represent their effects. A recent study by Geller et al. [2013] revealed large differences between such parameterizations and observations and pointed out the need in additional observational constraints.

During the recent decades numerous studies have addressed GW parameters and variability in the lower, middle, and upper atmosphere using various observation techniques. These studies made use of ground-based, in situ, and satellite observing systems that include lidars [e.g., Whiteway and Carswell, 1995; Rauthe et al., 2008; Mzé et al., 2014], radars [e.g., Sato, 1994], OH imagers [e.g., Suzuki et al., 2004], radiosondes [e.g., Wang and Geller, 2003], long-duration balloons [Hertzog et al., 2008], rockets [e.g., Eckermann et al., 1995] as well, and limb- and nadir-scanning satellites [Alexander et al., 2010, and references therein]. GPS radio occultation (RO) is one well-established limb technique, capable of providing global information on gravity waves. Temperature profiles from GPS/MET and CHAMP RO missions were used in a number of studies for constructing GW climatology [Tsuda et al., 2000; de la Torre et al., 2006; Hei et al., 2008]. A more elaborated Constellation Observing System for Meteorology, lonosphere and Climate (COSMIC) RO mission, operational since April 2006 and featuring global coverage, high vertical resolution, and sampling density [Anthes et al., 2008], was found to be of significant value for studying GW characteristics and climatology [e.g., Wright et al., 2011]. COSMIC observations lent themselves to a number of recent GW studies [S. P. Alexander et al., 2008a, 2008b; Wang and Alexander, 2010; McDonald, 2012; Faber et al., 2013].

A common problem of GW analyses, relying on a certain observation technique, is its limited altitude coverage. Only very few studies cover the entire altitude range relevant for gravity waves, that is from the troposphere to the mesosphere, using a combination of measurement techniques [Rauthe et al., 2008]. 
Meanwhile, there is an emerging need in precise information on GW both in the lower and middle atmosphere as many climate models now include the stratosphere component [Gerber et al., 2012]. A realistic representation of gravity waves is also essential for the reanalysis data sets such as ERA-Interim and Modern Era Retrospective-Analysis for Research and Applications (MERRA) because these are used as an input for many scientific applications, including operational weather forecasts [Orr et al., 2010].

The aim of this paper is to characterize the variability of GW potential energy at midlatitude upper troposphere and stratosphere (10 to $50 \mathrm{~km}$ ) using 7 years of temperature observations by COSMIC GPS and Rayleigh lidar in Southern France. The results are used to identify the variability factors and to evaluate GW representation in MERRA reanalysis.

\section{Data Sets and Methods}

\subsection{COSMIC GPS}

The Constellation Observing System for Meteorology, lonosphere and Climate (COSMIC), a joint U.S./Taiwanese radio occultation mission, is based on a constellation of six microsatellites providing 1500-2500 temperature profiles per day pseudo-randomly distributed around the globe. This translates into one to two profiles per day in a $5^{\circ} \times 5^{\circ}$ grid cell located at midlatitudes, which is where the sampling density is maximum. Vertical resolution ranges from $\sim 100 \mathrm{~m}$ in the lower troposphere to $1.4 \mathrm{~km}$ in the upper stratosphere [Anthes et al., 2008]. The total error in temperature estimated by Scherllin-Pirscher et al. [2011] amounts to $0.15 \mathrm{~K}$ between $10 \mathrm{~km}$ and $20 \mathrm{~km}$, increasing to about $0.4 \mathrm{~K}$ at $35 \mathrm{~km}$. This study uses COSMIC dry temperature profiles from COSMIC Data Analysis and Archive Center (CDACC) database in the 10 to $35 \mathrm{~km}$ vertical range, spanning from the mission start in April 2006 through April 2013.

The calculation of GW potential energy per unit of mass $E_{p}$ is done using two different methods. The first one follows closely [S. P. Alexander et al., 2008a]. In brief, the background temperature profile $\bar{T}$ is calculated from all individual profiles in a grid cell of $20^{\circ}$ longitude $\times 5^{\circ}$ latitude $\times 7$ days. Temperature perturbations $T^{\prime}$ are obtained by subtracting an individual profile's $T$ from the respective background $\bar{T}$ followed by removal of the vertical linear trend. The resulting profile is Welch-windowed and high-pass filtered with a cutoff at $7 \mathrm{~km}$. The $E_{p}$ for each profile, vertically averaged over $7 \mathrm{~km}$, is determined as

$$
E_{p}=\frac{1}{2}\left(\frac{g}{N}\right)^{2}\left(\frac{T^{\prime}}{\bar{T}}\right)^{2},
$$

where $g$ is the gravitational acceleration and $N$ is the Brunt-Väisälä frequency. The $E_{p}$ includes the waves with vertical wavelengths $\sim 2 \mathrm{~km}<\lambda_{z}<\sim 7 \mathrm{~km}$. The lower $\lambda_{z}$ limit is constrained by the COSMIC GPS observation technique and retrieval.

The second method for $E_{p}$ calculation uses fourth-order polynomial fitting function applied to each individual profile to obtain the background $\bar{T}$ profile [Wang and Geller, 2003]. The temperature perturbation profile is high-pass filtered to remove waves with $\lambda_{z}>7 \mathrm{~km}$. This method is applied here for constructing combined COSMIC/lidar time series of $E_{p}$ because it is more compatible with the lidar $E_{p}$ retrieval described below. Polynomial fitting yields higher $E_{p}$ in the vicinity of the tropopause and above $30 \mathrm{~km}$ as compared with the first method that tends to reduce wave amplitudes at the highest altitude due to Welch data windowing.

\subsection{Rayleigh Lidar}

Temperature soundings at 30 to $90 \mathrm{~km}$ altitude range are conducted by means of a Rayleigh lidar operating at Haute-Provence observatory, hereafter $\mathrm{OHP}\left(43.9^{\circ} \mathrm{N}, 5.7^{\circ} \mathrm{E}\right)$ since 1978 . Rayleigh backscattering of a laser beam in the absence of aerosols is used to measure atmospheric density and temperature [Hauchecorne and Chanin, 1980] with a sub-Kelvin accuracy up to $70 \mathrm{~km}$ [Keckhut et al., 1993]. The current system setup features vertical resolution of $0.075 \mathrm{~km}$ and temporal resolution of better than $3 \mathrm{~min}$. Here we use the nighttime measurements only spanning from January 2006 to April 2013 and totaling to 680 nights of lidar acquisitions. There is no data between mid-2010 and mid-2012 due to instrumental problems.

Temperature fluctuations are retrieved from raw lidar signals using a variance method [Hauchecorne et al., 1994; Mzé et al., 2014]. The method is based on the computation of the signal fluctuations over short temporal and vertical intervals followed by summation of the squares of these fluctuations over a large 
number of elementary intervals (here $\Delta T=26 \mathrm{~min}$ and $\Delta Z=1.125 \mathrm{~km}$, respectively), which gives an estimation of their variance. The observed variance of the lidar signal is defined as the sum of atmospheric and instrumental variances. The latter is estimated assuming a Poisson noise statistics for the photon counting signal. Then, the derived atmospheric variance together with Brunt-Väisälä frequency from a nightly mean temperature profile is used to calculate $\mathrm{GW} E_{p}$ between 33.5 and $50 \mathrm{~km}$. This method is equivalent to an estimation of the variance using a broad band-pass filter centered at a wavelength $\lambda \sim 2.4 \cdot \Delta Z$, which in our case translates into a spectral interval ranging from $\sim 2.2$ to $5.6 \mathrm{~km}$ at half maximum. The variance method is relatively simple but has the advantage of being robust and independent of data processing errors.

\subsection{MERRA Reanalysis}

The Modern Era Retrospective-Analysis for Research and Applications (MERRA) is a NASA reanalysis covering the modern satellite era from 1979 to the present with a $1 / 2^{\circ}$ latitude $\times 2 / 3^{\circ}$ longitude $\times 72$ layers model configuration [Rienecker et al., 2011]. Here we use MERRA 3-D analyzed 6-hourly fields on model levels from the surface up to $0.015 \mathrm{hPa}$. The retrieval of GW $E_{p}$ from MERRA temperature profiles is done similarly to COSMIC using two different methods described above.

\section{Results}

\subsection{Seasonal Variation of $E_{p}$}

In order to characterize the seasonal GW variability we combine COSMIC $E_{p}$ series with that of OHP lidar. The COSMIC $E_{p}$ is an average over $5^{\circ} \times 5^{\circ}$ domain centered at OHP, meaning that individual COSMIC profiles may be as far as $\sim 380 \mathrm{~km}$ apart from the time-correspondent lidar profiles. The two retrievals overlap in a narrow altitude range 33.5 to $35 \mathrm{~km}$. Intercomparison of $E_{p}$ values gives a fair agreement with a mean relative difference of $17.6 \%$ (lidar shows larger $E_{p}$ ) and correlation coefficient of 0.69 . The larger $E_{p}$ values from lidar may be due to its higher sensitivity to the waves with small $\lambda_{z}$, particularly at altitudes above $30 \mathrm{~km}$, where COSMIC vertical resolution becomes comparable with $\lambda_{z}$. In addition, the RO technique has a rather limited sensitivity to the waves with horizontal wavelength $\lambda_{h}$ smaller than a few hundreds of kilometers [Belloul and Hauchecorne, 1997], whereas the attenuation of the waves depends strongly on the orientation of their phases with respect to the line of sight [P. Alexander et al., 2008]. Despite this limitation of RO technique in GW detection, the COSMIC and lidar $E_{p}$ retrievals are in satisfactory agreement, which allows combining both data sets into a time series covering the entire stratosphere. A parabolic weighting function is applied to both retrievals in the overlapping region.

Figure 1 displays the resulting 7 year time series of GW $E_{p}$ vertical distribution above OHP between 10 and $50 \mathrm{~km}$ altitude. Monthly means of GW $E_{p}$ and zonal mean zonal wind are shown in Figure $1 \mathrm{a}$. The $E_{p}$ time series reveals a distinct pattern with GW activity maximizing throughout the stratosphere during the winter, which is during the maximum westerly winds above $20 \mathrm{~km}$. In addition, there is a notable interannual variability both in the lower and upper stratosphere. A decrease of GW $E_{p}$ below $1 \mathrm{~J} \mathrm{~kg}^{-1}$ is observed in the midstratosphere ( 15 to $40 \mathrm{~km}$ ) from late spring to late fall with a minimum during summer at $\sim 24 \mathrm{~km}$. The upper boundary of this stratospheric layer of suppressed GW activity is visible thanks to the combined GPS/lidar series. The minimum $E_{p}$ values correspond to the summertime easterly winds. Since the tropospheric winds are generally westerly at these latitudes throughout the year, the stationary waves are blocked from entering the stratosphere during summer, being filtered-out at the level where zonal wind changes direction. This phenomenon, referred to as critical level filtering, is described for instance by Whiteway and Duck [1996].

Figure $1 \mathrm{~b}$ shows a time series of COSMIC/lidar $E_{p}$ weekly means superposed by MERRA $E_{p}$ monthly means, calculated for the same area above OHP. One can see a week-to-week variability of COSMIC $E_{p}$, which is discernible even during summertime midstratosphere GW depression. The highest week-to-week variability with $E_{p}$ changing by an order of magnitude is observed around the tropopause, i.e., between 10 and $13 \mathrm{~km}$. While this variability may be associated with the local meteorological phenomena, such as thunderstorms or fronts, one should bear in mind that $E_{p}$ in this layer is most likely overestimated due to abrupt changes in tropopause structure, which may be aliased as wave-induced fluctuations.

Also, of interest in Figure $1 \mathrm{~b}$ is the $E_{p}$ series retrieved from MERRA data and its comparison with COSMIC. The monthly means of MERRA $E_{p}$ reveal a seasonal pattern consistent with the observations in terms of the wintertime maximum. However, according to MERRA, $E_{p}$ obtains a negative vertical gradient above $\sim 45 \mathrm{~km}$, 
a)

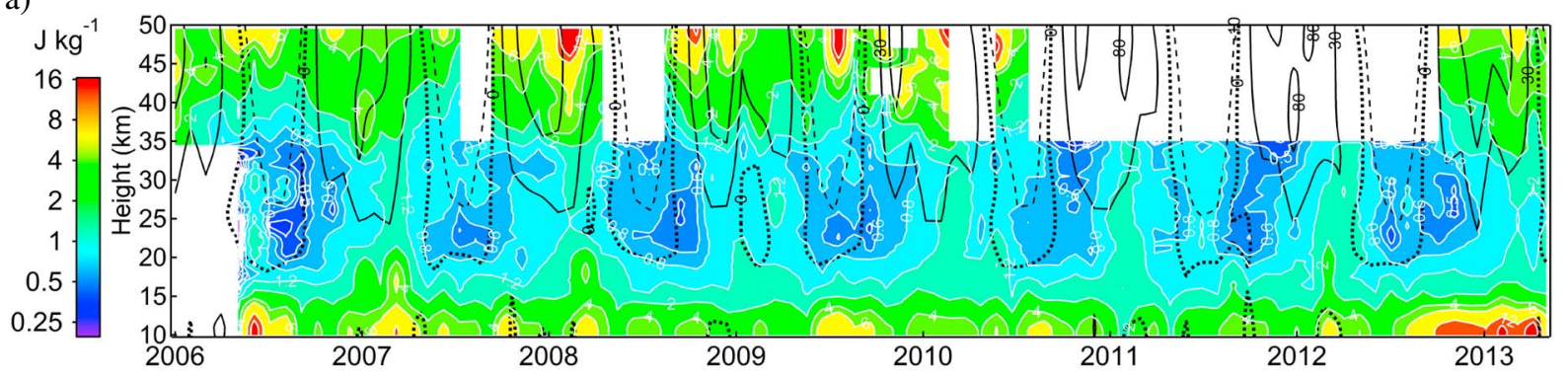

b)

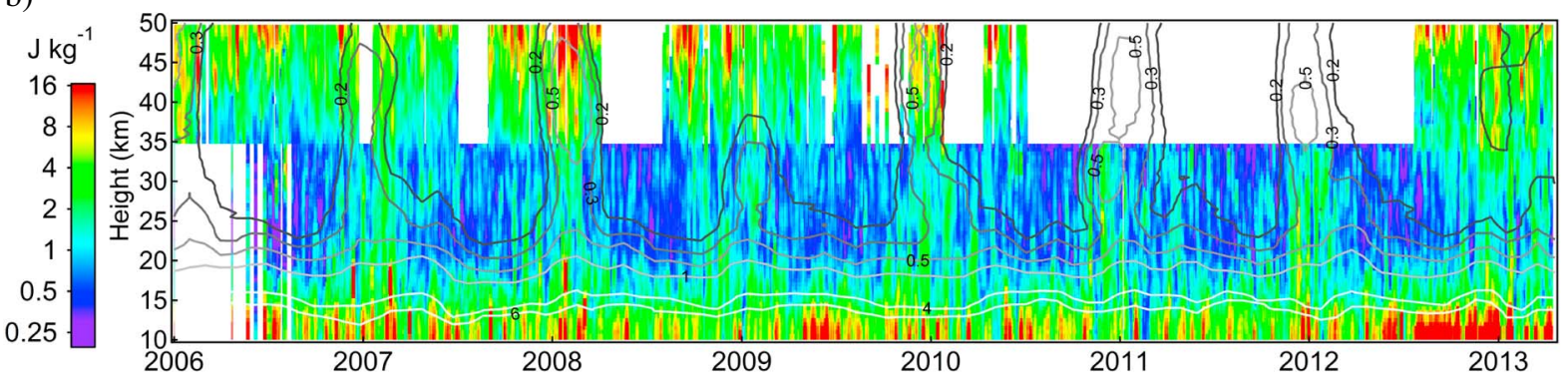

Figure 1. Combined time series of GW $E_{p}$ from Rayleigh lidar at $\mathrm{OHP}\left(44^{\circ} \mathrm{N}, 6^{\circ} \mathrm{E}\right)$ and $\operatorname{COSMIC}\left(5^{\circ} \times 5^{\circ}\right.$ domain centered at $\left.\mathrm{OHP}\right)$. White areas represent the missing data. (a) Monthly mean $E_{p}$ (color map) and zonal wind (solid contours, westerly winds of 30 and $80 \mathrm{~m} / \mathrm{s}$; dotted contour, zero wind; dashed contour, easterly wind of $10 \mathrm{~m} / \mathrm{s}$ ). (b) Weekly means of $E_{p}$ from COSMIC and lidar (color map) and monthly means of MERRA $E_{p}$ (gray-scaled contours, denoting $0.2,0.3,0.5,1,2,4$, and 6 units of $\mathrm{J} \mathrm{kg}^{-1}$ ).

which contradicts with lidar observations at OHP [Mzé et al., 2014]. Note also that the absolute values of $E_{p}$ in the midstratosphere are about an order of magnitude lower than those from COSMIC/lidar. These differences likely arise from low vertical resolution of MERRA in the stratosphere, which results in severe filtering of the waves. The same effect is reported by Schroeder et al. [2009] for European Centre for Medium-Range Weather Forecasts (ECMWF) data compared against satellite observations.

GW $E_{p}$ variability on a shorter time scale seen by COSMIC/lidar and MERRA is shown in Figure 2, providing a zoom into a 6 month period around the turn of the year 2013. A remarkable feature is a strong increase of $E_{p}$ above $37 \mathrm{~km}$ detected by the lidar in late December to early January. This enhancement reflects a strong dynamical perturbation in the middle atmosphere, which leaded to a major sudden stratospheric warming

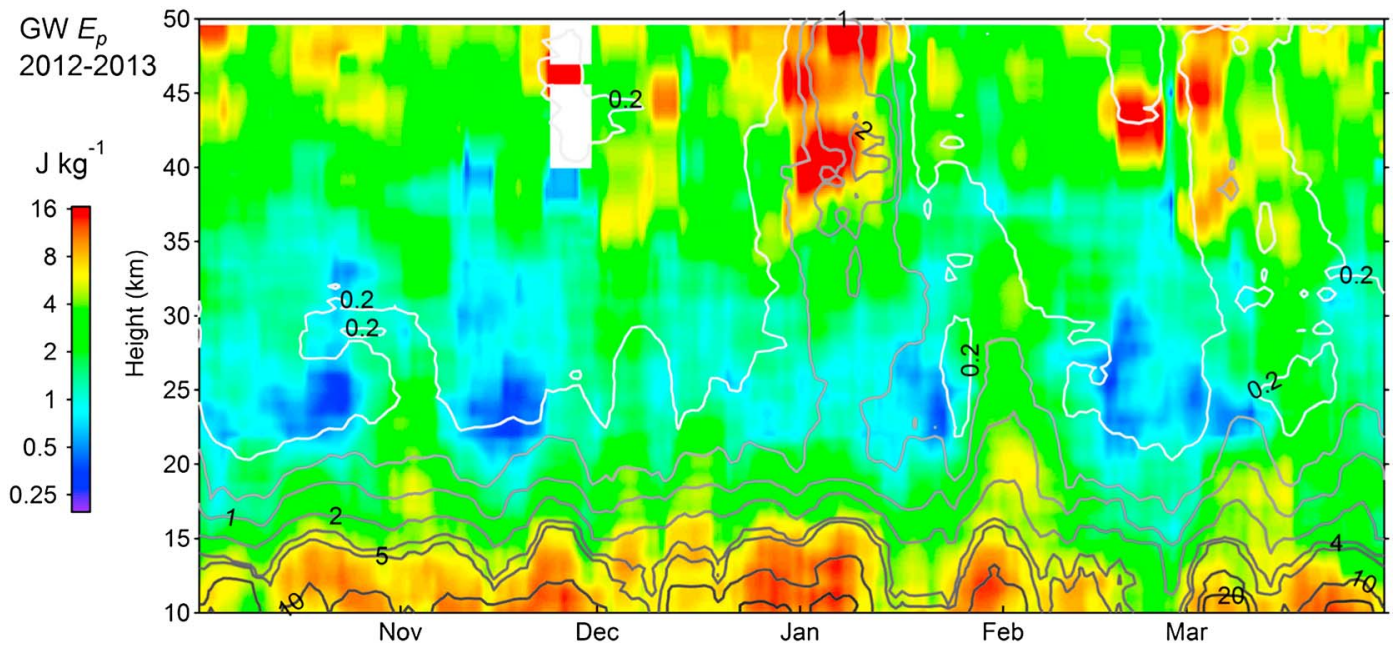

Figure 2. Same as Figure 1b for the period October 2012 to April 2013. 
a)

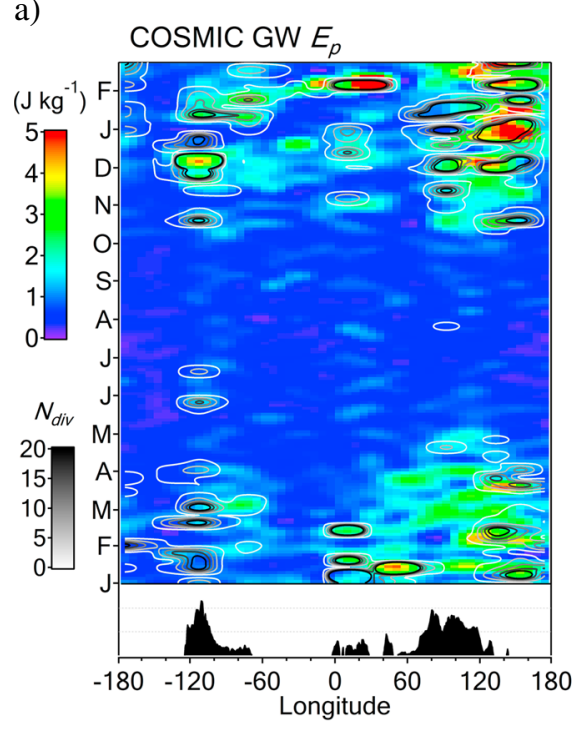

b)

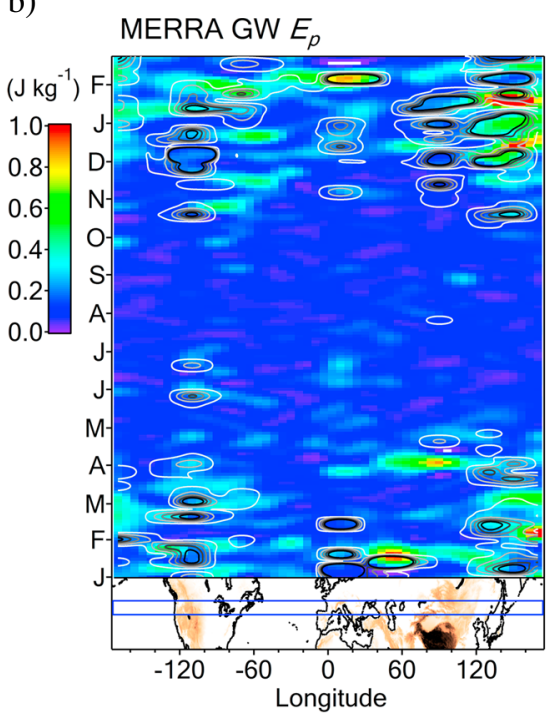

c)

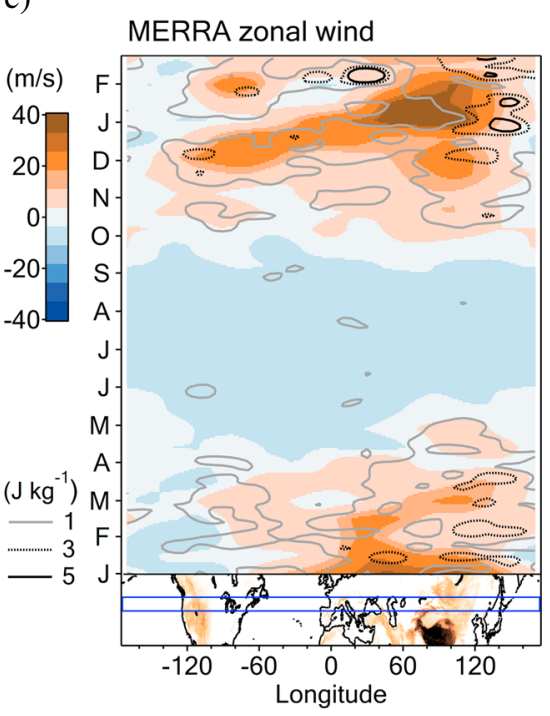

Figure 3. Longitude-time variations (January 2012 to March 2013) within 20-24 km altitude layer of (a) GW $E_{p}$ from COSMIC (color map) and wind divergence anomalies (gray-scaled contours), (b) same as Figure 3a but with GW $E_{p}$ from MERRA (note the different color scales), and (c) zonal wind (color map) and COSMIC GW $E_{p}$ (contours). The topographic profile (Figure $3 \mathrm{a}$ ) and map of continents with topography (Figures $3 \mathrm{~b}$ and $3 \mathrm{c}$ ) are provided in the bottom of each panel. The blue rectangle marks the latitude belt considered $\left(44^{\circ} \mathrm{N} \pm 2.5^{\circ}\right)$.

(SSW) with an onset on 7 January [de Wit et al., 2014]. Note that the increase of GW energy begins above the stratopause (located at $\sim 45 \mathrm{~km}$ ) around mid-December and extends down to $37 \mathrm{~km}$ in late December.

MERRA correctly reproduces the vertical structure and the temporal extent of the SSW-related enhancement but underestimates $E_{p}$ by about an order of magnitude. Similarly, MERRA resolves most of the $E_{p}$ enhancements in the upper and middle stratosphere, showing GW activity pattern consistent with the observations, but with reduced magnitude. In contrast, MERRA $E_{p}$ in the lowermost stratosphere, below about $15 \mathrm{~km}$, is fully consistent with COSMIC $E_{p}$, both in structure and absolute values. Indeed, the vertical resolution of MERRA in this layer is very close to that of COSMIC, which allows capturing a wider spectrum of waves.

\subsection{Zonal Variation of $E_{p}$}

Figure 3 displays Hovmoller plots of GW $E_{p}$ and zonal wind longitude-time variation in the middle stratosphere within a $5^{\circ}$ latitude belt centered at OHP latitude. The $E_{p}$ fields from COSMIC (Figure $3 a$ ) and MERRA (Figure $3 \mathrm{~b}$ ) are obtained using grid cell background temperature (first $E_{p}$ retrieval method, see section 2.1). The MERRA $E_{p}$ is calculated after interpolation of reanalysis data onto the locations of COSMIC occultations. Thus, MERRA $E_{p}$ field is constructed using the same spatiotemporal sampling as that of COSMIC observations.

As already pointed out above, GW activity is enhanced from November to April, during the period of westerly winds (see Figure $3 \mathrm{c}$ ). The Hovmoller plots reveal a notable zonal variability of $E_{p}$, showing GW manifestations above the continents, more precisely above the regions with high topography: Rockies, Alps, and downwind of Tian Shan as well as above North-East China and Hokkaido island. Similar correspondences were reported before, e.g., by Eckermann and Preusse [1999]. The temporal $E_{p}$ variation above these areas can be described as several episodes of enhanced GW activity with potential energy changing rapidly from the background values $\left(<1 \mathrm{~J} \mathrm{~kg}^{-1}\right)$ to $>5 \mathrm{~J} \mathrm{~kg}^{-1}$. Both longitude and temporal distributions of GW activity appear to be strongly dependent on stratospheric zonal winds, as suggested by Figure 3c. Strong (westerly) winds, characteristic of the midlatitude winter stratosphere, favor stratospheric GW activity, whereas the easterly winds filter out nearly all wave energy entering the stratosphere.

The longitude-time pattern and most of the GW activity episodes seen by COSMIC are resolved by MERRA (Figure $3 \mathrm{~b}$ ) and by ERA-Interim (not shown). However, both reanalyses underestimate $E_{p}$ by a factor of 4 to 7 during these GW events (note the different color scales in Figures $3 a$ and $3 b$ ). This finding is consistent with a 
number of previous studies [Preusse et al., 2014, and references therein], showing that ECMWF correctly reproduces the temporal and spatial variations of GW activity, whereas GW potential energy and momentum flux are too low.

A consideration regarding the possible sources of gravity waves is done by analyzing the perturbations in the mean flow. For that we examine horizontal wind divergence fields at a regular $1.125^{\circ} \times 1.125^{\circ}$ latitude/longitude grid-a product of ERA-Interim reanalysis [Dee et al., 2011]. Horizontal wind divergence DIV is often used as a dynamical indicator of internal gravity waves [e.g., Plougonven et al., 2003]. While the majority of GW studies use DIV as a qualitative indicator of the horizontal structure of the waves, we attempt to relate the magnitude of the wind divergence to manifestations of gravity waves-an approach applied by Dörnbrack et al. [2012]. The wave activity events are diagnosed by counting localized anomalies of the wind divergence exceeding a certain threshold. We use an arbitrary threshold DIV $_{t}=1 \times 10^{-4} \mathrm{~s}^{-1}$ for counting all occurrences of $|\mathrm{DIV}|>\mathrm{DIV}_{t}, N_{\text {div }}$ in every $E_{p}$ longitude-time grid cell. The resulting distribution of $N_{\text {div }}$ is shown in gray-scaled contours in Figures $3 a$ and $3 b$. The spatiotemporal correlation between $E_{p}$ and $N_{\text {div }}$ enhancements is remarkable-nearly all GW manifestations detected by COSMIC are characterized by an enhanced wind divergence as well as the other way around. For most events the magnitude of $E_{p}$ enhancement relates to that of divergence. The correlation between $E_{p}$ and $N_{\text {div }}$ fields is qualitatively lower for MERRA.

\section{Discussion}

The annual cycle of stratospheric GW activity at midlatitudes with a minimum during the summer and a maximum during the winter has been reported in a number of studies (several quoted in section 1) using various sets of local and global observations. Despite the fact that these studies relied on different observation techniques and $E_{p}$ retrieval methods, hence involving different parts of the wave spectrum, they all report the winter maximum of GW activity.

The enhanced wave activity in the winter midlatitude stratosphere may be caused by various factors. First, it is the reduced wind filtering of stationary waves, generated by the flow over orography. This is supported by the zonal distribution of $E_{p}$ at 20-24 km layer, increasing above the rough terrain regions (Figure 3a) and within the areas of the strongest stratospheric westerlies at the same layer (Figure 3c). The sensitivity of wave propagation to wind velocity suggests that the spectrum of GW detected by our analysis is dominated by slow-phase speed waves.

Second, stratospheric GWs may be induced by nonorographic sources such as geostrophic adjustment of the jet [Plougonven and Zhang, 2014]. Plougonven et al. [2003] suggested that the waves generated in the regions of high curvature of the jet are large-scale inertia-gravity waves with vertical wavelengths typically between 2 and $3 \mathrm{~km}$. Because they are due to the evolution of the large-scale flow (often caused by planetary wave activity), a reanalysis can provide qualitative indication of their location on the maps of divergence. This is confirmed by the correlation between $E_{p}$ and $N_{\text {div }}$ fields (Figures $3 a$ and $3 b$ ).

Third, enhanced stratospheric GW activity is often observed before and during the SSW events. This is associated with planetary wave transience and/or breaking [Hei et al., 2008; Yamashita et al., 2010], generation of waves near the vortex edge by adjustment of the unbalanced flow [Limpasuvan et al., 2011], and refraction (Doppler shifting) of the waves to observable wavelengths in the weakening winds. The latter is referred to as an observational window effect introduced by Alexander [1998] and applied by, e.g., Wang and Alexander [2009]. This consideration can explain the increasing GW activity in the upper stratosphere above OHP in late December 2012 (Figure 2) corresponding to the zonal wind deceleration in the upper stratosphere, as inferred from MERRA (not shown). A detailed investigation of GW activity behavior during SSW using OHP lidar observations will be a subject of a separate paper.

\section{Summary}

We use temperature data provided by COSMIC GPS and Rayleigh lidar operating at OHP, Southern France to construct 7 year time series of GW potential energy, $E_{p}$ in the stratosphere. The two data sets provide consistent information on GW activity, which allows combining the two $E_{p}$ retrievals in a single series covering the entire stratosphere (10 to $50 \mathrm{~km}$ ). We observe a distinct pattern with GW activity maximizing throughout the stratosphere during the winter and a wide layer of suppressed GW activity in the midstratosphere during 
summer. The vertical distribution of $E_{p}$ exhibits a maximum around the tropopause and, as expected from theory, a general growth of wave energy with altitude.

The observed seasonal variation of stratospheric GW activity is found mainly driven by the wind filtering process. This way, the summer minimum, corresponding to the weak easterlies, is due to filtering out of the tropospheric waves at the critical level, where zonal wind changes direction. In contrast, the unidirectional westerly zonal winds during the winter allow the waves to propagate into the stratosphere. High sensitivity of GW vertical propagation to zero wind critical filtering suggests that the source spectrum is dominated by quasi-stationary waves, presumably of orographic origin.

Examination of $E_{p}$ zonal variability reveals enhanced GW activity above the continents and more specifically above the regions with elevated terrain, suggesting an orographic origin of the observed waves. The longitude distribution of GW activity is also found to be determined by the strength of the jet. Further, we find an apparent spatiotemporal correlation between GW enhancements and stratospheric wind divergence, suggesting nonorographic wave sources.

We report a dramatic increase of GW activity in the upper stratosphere above OHP before and during the SSW event in early January 2013. This is attributed to planetary wave activity, which strongly perturbs the zonal winds in the middle atmosphere, resulting in wave generation by adjustment of the unbalanced flow. The weakening winds preceding the SSW refract the waves to shorter vertical wavelengths making them observable by our analysis (observational window effect).

Overall, we find indications of the two main sources of gravity waves detected by COSMIC and lidar in the stratosphere: (i) orographic generation and upward propagation and (ii) nonorographic generation by geostrophic adjustment of the flow. The seasonal variability of GW activity can be largely explained by the wave propagation considerations, particularly (i) critical level filtering, acting to block the waves from propagation into the stratosphere and (ii) wave refraction (Doppler shifting) coupled with observational filter effect. Our results and their interpretation are fully consistent with those provided in earlier studies on GW variability in the midlatitude stratosphere, quoted above.

Synergetic use of satellite (COSMIC) and ground-based (lidar) observations allowed us to examine GW variability at a broad altitude range inaccessible with a single observation technique. The combined series were used to evaluate the representation of GW in MERRA reanalysis. We found that the basic features of GW seasonal variability along with the location of the major GW enhancements are correctly reproduced by the reanalysis; however, the magnitude of wave energy in the middle and upper stratosphere is severely underestimated by the model. Finally, we point out that anomalies in the wind divergence inferred from reanalysis data can serve as a proxy for locating synoptic-scale enhancements of GW activity.

\section{Acknowledgments}

The work was supported by EU FP7 ARISE project (284387) and the French ANR StraDyVariUS project. We thank Andreas Dörnbrack and anonymous reviewers for their fruitful comments, which helped improving the manuscript. Lidar measurements at Haute Provence observatory were obtained in the frame of NDACC (Network for the Detection of Atmospheric Composition Change) with the support from CNRS-INSU, CNES, and UVSQ. The COSMIC RO data used in this study are those available from the Data Analysis and Archive Centre (CDAAC) of the University Corporation for Atmospheric Research (http://cdaacwww.cosmic.ucar.edu/cdaac/).

The Editor thanks three anonymous reviewers for their assistance in evaluating this paper.

\section{References}

Alexander, M. J. (1998), Interpretations of observed climatological patterns in stratospheric gravity wave variance, J. Geophys. Res., 103, 8627-8640, doi:10.1029/97JD03325.

Alexander, M. J., et al. (2010), Recent developments in gravity-wave effects in climate models and the global distribution of gravity-wave momentum flux from observations and models, Q. J. R. Meteorol. Soc., 136, 1103-1124, doi:10.1002/qj.637.

Alexander, P., A. de la Torre, and P. Llamedo (2008), Interpretation of gravity wave signatures in GPS radio occultations, J. Geophys. Res., 113, D16117, doi:10.1029/2007JD009390.

Alexander, S. P., T. Tsuda, and Y. Kawatani (2008a), COSMIC GPS observations of Northern Hemisphere winter stratospheric gravity waves and comparisons with an atmospheric general circulation model, Geophys. Res. Lett., 35, L10808, doi:10.1029/2008GL033174.

Alexander, S. P., T. Tsuda, Y. Kawatani, and M. Takahashi (2008b), Global distribution of atmospheric waves in the equatorial upper troposphere and lower stratosphere: COSMIC observations of wave mean flow interactions, J. Geophys. Res., 113, D24115, doi:10.1029/ 2008JD010039.

Anthes, R. A., et al. (2008), The COSMIC/FORMSAT-3 mission early results, Bull. Am. Meteorol. Soc., 89(3), 313-333, doi:10.1175/BAMS-89-3-313.

Belloul, M. B., and A. Hauchecorne (1997), Effect of periodic horizontal gradients on the retrieval of atmospheric profiles from occultation measurements, Radio Sci., 32, 469-478, doi:10.1029/96RS03599.

de la Torre, A., T. Schmidt, and J. Wickert (2006), A global analysis of wave potential energy in the lower stratosphere derived from 5 years of GPS radio occultation data with CHAMP, Geophys. Res. Lett., 33, L24809, doi:10.1029/2006GL027696.

de Wit, R. J., R. E. Hibbins, P. J. Espy, Y. J. Orsolini, V. Limpasuvan, and D. E. Kinnison (2014), Observations of gravity wave forcing of the mesopause region during the January 2013 major Sudden Stratospheric Warming, Geophys. Res. Lett., 41, 4745-4752, doi:10.1002/2014GL060501.

Dee, D. P., et al. (2011), The ERA-Interim reanalysis: Configuration and performance of the data assimilation system, Q. J. R. Meteorol. Soc., 137, 553-597, doi:10.1002/qj.828.

Dörnbrack, A., M. C. Pitts, L. R. Poole, Y. J. Orsolini, K. Nishii, and H. Nakamura (2012), The 2009-2010 Arctic stratospheric winter-General evolution, mountain waves and predictability of an operational weather forecast model, Atmos. Chem. Phys., 12, 3659-3675, doi:10.5194/ acp-12-3659-2012. 
Eckermann, S. D., and P. Preusse (1999), Global measurements of stratospheric mountain waves from space, Science, 286, 1534-1537. Eckermann, S. D., I. Hirota, and W. K. Hocking (1995), Gravity wave and equatorial wave morphology of the stratosphere derived from long-term rocket soundings, Q. J. R. Meteorol. Soc., 121, 149-186, doi:10.1256/smsqj.52107.

Faber, A., P. Llamedo, T. Schmidt, A. de la Torre, and J. Wickert (2013), On the determination of gravity wave momentum flux from GPS radio occultation data, Atmos. Meas. Tech., 6, 3169-3180, doi:10.5194/amt-6-3169-2013.

Fritts, D., and M. Alexander (2003), Gravity wave dynamics and effects in the middle atmosphere, Rev. Geophys., 41(1), 1003, doi:10.1029/ 2001 RG000106.

Geller, M., et al. (2013), A comparison between gravity wave momentum fluxes in observations and climate models, J. Clim., 26, 6383-6405, doi:10.1175/JCLI-D-12-00545.1.

Gerber, E. P., et al. (2012), Assessing and understanding the impact of stratospheric dynamics and variability on the Earth system, Bull. Am. Meteorol. Soc., 93, 845-859.

Hauchecorne, A., and M. L. Chanin (1980), Density and temperature profiles obtained by lidar between 35 and 70 km, Geophys. Res. Lett., 7(8), 565-568, doi:10.1029/GL007i008p00565.

Hauchecorne, A., et al. (1994), Gravity-wave activity and its relation with prevailing winds during DYANA, J. Atmos. Terr. Phys., 56(13), 1765-1778.

Hei, H., T. Tsuda, and T. Hirooka (2008), Characteristics of atmospheric gravity wave activity in the polar regions revealed by GPS radio occultation data with CHAMP, J. Geophys. Res., 113, D04107, doi:10.1029/2007JD008938.

Hertzog, A., G. Boccara, R. Vincent, F. Vial, and P. Coquerez (2008), Estimation of gravity-wave momentum fluxes and phase speeds from long-duration stratospheric balloon flights: 2. Results from the Vorcore campaign in Antarctica, J. Atmos. Sci, 65, 3056-3070.

Holton, J. R. (1992), An Introduction to Dynamic Meteorology, 3rd ed., Academic Press, London.

Keckhut, P., A. Hauchecorne, and M. L. Chanin (1993), A critical review of the database acquired for the long-term surveillance of the middle atmosphere by the French Rayleigh lidars, J. Atmos. Oceanic Tech., 10, 850-867.

Limpasuvan, V., M. J. Alexander, Y. J. Orsolini, D. L. Wu, M. Xue, J. H. Richter, and C. Yamashita (2011), Mesoscale simulations of gravity waves during the 2008-2009 major stratospheric sudden warming, J. Geophys. Res., 116, D17104, doi:10.1029/2010JD015190.

McDonald, A. J. (2012), Gravity wave occurrence statistics derived from paired COSMIC/FORMOSAT3 observations, J. Geophys. Res., 117, D15106, doi:10.1029/2011JD016715.

Mzé, N., A. Hauchecorne, P. Keckhut, and M. Thétis (2014), Vertical distribution of gravity wave potential energy from long-term Rayleigh lidar data at a northern middle-latitude site, J. Geophys. Res. Atmos., 119, 12,069-12,083, doi:10.1002/2014JD022035.

Orr, A., P. Bechtold, J. Scinocca, M. Ern, and M. Janiskova (2010), Improved middle atmosphere climate and forecasts in the ECMWF mode through a nonorographic gravity wave drag parameterization, J. Clim., 23, 5905-5926.

Plougonven, R., and F. Zhang (2014), Internal gravity waves from atmospheric jets and fronts, Rev. Geophys., 52, 33-76, doi:10.1002/ 2012 RG000419.

Plougonven, R., H. Teitelbaum, and V. Zeitlin (2003), Inertia gravity wave generation by the tropospheric midlatitude jet as given by the Fronts and Atlantic Storm-Track Experiment radio soundings, J. Geophys. Res., 108(D21), 4686, doi:10.1029/2003JD003535.

Preusse, P., M. Ern, P. Bechtold, S. D. Eckermann, S. Kalisch, Q. T. Trinh, and M. Riese (2014), Characteristics of gravity waves resolved by ECMWF, Atmos. Chem. Phys., 14, 10,483-10,508, doi:10.5194/acp-14-10483-2014.

Rauthe, M., M. Gerding, and F.-J. Lübken (2008), Seasonal changes in gravity wave activity measured by lidars at mid-latitudes, Atmos. Chem. Phys., 8, 6775-6787, doi:10.5194/acp-8-6775-2008.

Rienecker, M. M., et al. (2011), MERRA: NASA's Modern-Era Retrospective Analysis for Research and Applications, J. Clim., 24, 3624-3648, doi:10.1175/JCLI-D-11-00015.1.

Sato, K. (1994), A statistical study of the structure, saturation and sources of inertio-gravity waves in the lower stratosphere observed with the MU radar, J. Atmos. Terr. Phys., 56, 755-774.

Scherllin-Pirscher, B., A. K. Steiner, G. Kirchengast, Y.-H. Kuo, and U. Foelsche (2011), Empirical analysis and modeling of errors of atmospheric profiles from GPS radio occultation, Atmos. Meas. Tech., 4, 1875-1890, doi:10.5194/amt-4-1875-2011.

Schroeder, S., P. Preusse, M. Ern, and M. Riese (2009), Gravity waves resolved in ECMWF and measured by SABER, Geophys. Res. Lett., 36, L10805, doi:10.1029/2008GL037054.

Suzuki, S., K. Shiokawa, Y. Otsuka, T. Ogawa, and P. Wilkinson (2004), Statistical characteristics of gravity waves observed by an all-sky imager at Darwin, Australia, J. Geophys. Res., 109, D20S07, doi:10.1029/2003JD004336.

Tsuda, T., M. Nishida, C. Rocken, and R. H. Ware (2000), A global morphology of gravity wave activity in the stratosphere revealed by the GPS occultation data (GPS/MET), J. Geophys. Res., 105, 7257-7273, doi:10.1029/1999JD901005.

Wang, L., and M. J. Alexander (2009), Gravity wave activity during stratospheric sudden warmings in the 2007-2008 Northern Hemisphere winter, J. Geophys. Res., 114, D18108, doi:10.1029/2009JD011867.

Wang, L., and M. J. Alexander (2010), Global estimates of gravity wave parameters from GPS radio occultation temperature data, J. Geophys. Res., 115, D21122, doi:10.1029/2010JD013860.

Wang, L., and M. A. Geller (2003), Morphology of gravity-wave energy as observed from 4 years (1998-2001) of high vertical resolution U.S. radiosonde data, J. Geophys. Res., 108(D16), 4489, doi:10.1029/2002JD002786.

Whiteway, J. A., and A. I. Carswell (1995), Lidar observations of gravity wave activity in the upper stratosphere over Toronto, J. Geophys. Res., 100, 14,113-14,124, doi:10.1029/95JD00511.

Whiteway, J. A., and T. J. Duck (1996), Evidence for critical level filtering of atmospheric gravity waves, Geophys. Res. Lett., 23, 145-148, doi:10.1029/95GL03784.

Wright, C. J., M. B. Rivas, and J. C. Gille (2011), Intercomparisons of HIRDLS, COSMIC and SABER for the detection of stratospheric gravity waves, Atmos. Meas. Tech., 4, 1581-1591, doi:10.5194/amt-4-1581-2011.

Yamashita, C., H. L. Liu, and X. Chu (2010), Gravity wave variations during the 2009 stratospheric sudden warming as revealed by ECMWF-T799 and observations, Geophys. Res. Lett., 37, L22806, doi:10.1029/2010GL045437. 